\title{
Early Transplantation of Bone Marrow Mononuclear Cells Promotes Neuroprotection and Modulation of Inflammation After Status Epilepticus in Mice by Paracrine Mechanisms
}

\author{
Marcos Maurício Tosta Leal • Zaquer Suzana Munhoz Costa-Ferro • \\ Bruno Solano de Freitas Souza - Carine Machado Azevedo • Thiago Meneses Carvalho • \\ Carla Martins Kaneto • Rejane Hughes Carvalho • Ricardo Ribeiro dos Santos • \\ Milena Botelho Pereira Soares
}

Received: 22 July 2013/Revised: 29 November 2013/Accepted: 7 December 2013/Published online: 17 December 2013

(C) Springer Science+Business Media New York 2013

\begin{abstract}
Status epilepticus (SE) is a severe clinical manifestation of epilepsy associated with intense neuronal loss and inflammation, two key factors involved in the pathophysiology of temporal lobe epilepsy. Bone marrow mononuclear cells (BMMC) attenuated the consequences of pilocarpine-induced SE, including neuronal loss, in addition to frequency and duration of seizures. Here we investigated the effects of BMMC transplanted early after the onset of SE in mice, as well as the involvement of soluble factors produced by BMMC in the effects of the cell therapy. Mice were injected with pilocarpine for SE induction and randomized into three groups: transplanted intravenously with $1 \times 10^{7}$ BMMC isolated from GFP transgenic mice, injected with BMMC lysate, and saline-treated controls. Cell tracking, neuronal counting in hippocampal subfields and cytokine analysis in the serum and brain were performed. BMMC were found in the brain $4 \mathrm{~h}$ following transplantation and their numbers progressively decreased until $24 \mathrm{~h}$ following transplantation. A reduction in hippocampal neuronal loss after SE was found in mice treated with live BMMC and BMMC lysate when compared to saline-treated, SE-induced mice. Moreover, the expression of inflammatory cytokines IL-1 $\beta$, TNF- $\alpha$, IL- 6 was decreased after injection
\end{abstract}

M. M. T. Leal · Z. S. M. Costa-Ferro .

B. S. F. Souza - C. M. Azevedo - T. M. Carvalho ·

C. M. Kaneto - R. H. Carvalho · R. R. dos Santos .

M. B. P. Soares

Hospital São Rafael, Av. São Rafael, 2152. São Marcos,

Salvador, BA 41253-190, Brazil

B. S. F. Souza - C. M. Azevedo - M. B. P. Soares $(\square)$ Centro de Pesquisas Gonçalo Moniz, Fundação Oswaldo Cruz, Rua Waldemar Falcão, 121. Candeal, Salvador, BA 40296-710, Brazil

e-mail: milenabpsoares@gmail.com; milena@bahia.fiocruz.br of live BMMC and to a lesser extent, of BMMC lysate, when compared to SE-induced controls. In contrast, IL-10 expression was increased. Analysis of markers for microglia activation demonstrated a reduction of the expression of genes related to type 1-activation. BMMC transplantation promotes neuroprotection and mediates anti-inflammatory effects following SE in mice, possibly through the secretion of soluble factors.

Keywords Status epilepticus - Bone marrow mononuclear cells · Cytokines · Inflammation . Pilocarpine

$\begin{array}{ll}\text { Abbreviations } \\ \text { CA1 } & \text { Cornu ammonis region 1 } \\ \text { CA3 } & \text { Cornu ammonis region } 3 \\ \text { i. v } & \text { Intravenous } \\ \text { TNF } \alpha & \text { Tumor necrosis factor- } \alpha \\ \text { IL-1 } \beta & \text { Interleukin } 1 \beta \\ \text { IL-4 } & \text { Interleukin } 4 \\ \text { IL-6 } & \text { Interleukin } 6 \\ \text { IL-10 } & \text { Interleukin } 10 \\ \text { NOS2 } & \text { Nitric oxide synthase 2 } \\ \text { Chi313 } & \text { Chitinase 3-like 3 } \\ \text { MRC1 } & \text { Mannose receptor C type 1 } \\ \text { CCL 22 } & \text { Chemokine (C-C motif) ligand } 22 \\ \text { CCL 17 } & \text { Chemokine (C-C motif) ligand } 17 \\ \text { ARG1 } & \text { Arginase 1 }\end{array}$

\section{Introduction}

Status epilepticus (SE) can be induced in rodents by systemic administration of pilocarpine, a non-subtype-specific partial muscarinic receptor agonist. This experimental 
model resembles human temporal lobe epilepsy (TLE) [13]. SE is a severe clinical manifestation of epilepsy that can lead to functional and structural consequences as a result of the injured brain [4]. It is well known that a number of physiological and neurochemical alterations take place during the seizure activity [5].

Currently, experimental and clinical data have demonstrated the involvement of the inflammatory processes in TLE pathogenesis. Rodent and human TLE studies have demonstrated a role for pro-epileptogenic inflammatory cytokines, such as IL-6, TNF $\alpha$, and the IL-1 family [6-11]. Microglia cells are major contributors to the inflammatory process, as well as the establishment of epilepsy. Thus, experimental strategies that suppress neuroinflammation, directly within the central nervous system (CNS), or modulate systemic inflammation, have both been shown to promote amelioration of epilepsy [12-14].

Bone marrow mononuclear cells (BMMC) are a heterogeneous population comprised of both stem cells and progenitor cells with potential therapeutic value to boost tissue repair and regeneration in some disease conditions. In the field of neurology, BMMC have been shown to promote neuronal regeneration in ischemic cerebrovascular diseases [15-17], spinal cord injury [18, 19], autoimmune encephalomyelitis [20], multiple sclerosis [21], Parkinson's disease [22], Alzheimer's disease [23], Huntington's disease [24], amyotrophic lateral sclerosis [25, 26], and epilepsy [27-29].

We have previously demonstrated that transplantation of BMMC immediately after the onset of SE prevents neuronal cell loss and development of spontaneous recurrent seizures [27]. In this study we investigated the effects of BMMC transplantation following SE by using an experimental model of pilocarpine in mice. Moreover, we evaluated the mechanistic involvement of soluble factors in cell therapy, by using lysate BMMC.

\section{Materials and Methods}

\section{Animals and Experimental Procedures}

This study was conducted after the approval from the local Ethics Committee for Animal Care and Use from Hospital São Rafael (05/2010). C57BL/6-Tg(CAG-EGFP)1Osb/J (The Jackson Laboratory, ME, USA), which express the enhanced Green Fluorescent Protein (GFP) under the control of a chicken beta-actin promoter and cytomegalovirus enhancer, were used as bone marrow donors, and Swiss Webster mice were used as recipients. All mice included in this study weighted $25-35 \mathrm{~g}$ and were 6-8 weeks of age. The animals had free access to food and water and were maintained in a room controlling for temperature $\left(22-24{ }^{\circ} \mathrm{C}\right)$, humidity $(60 \%)$, and light-dark cycle (12 h).

In order to induce $\mathrm{SE}$, mice received a single dose of pilocarpine $(220 \mathrm{mg} / \mathrm{kg}$, i.p; Sigma-Aldrich, St. Louis, MO, USA). To prevent peripheral cholinergic side effects, methylscopolamine (1 mg/kg, i.p.; Sigma-Aldrich) was administered $30 \mathrm{~min}$ prior to pilocarpine injection. Mice were placed in cages and seizure occurrence and duration were observed. Mice presenting stage V seizures, according to Racine scale [30], were included in this study. Two hours after the onset of SE, diazepam $(10 \mathrm{mg} / \mathrm{kg}$, i.p. Cristália, Itapira, Brazil) was administered to block seizures. These mice were randomized into different experimental groups, administered with (1) BMMC; (2) BMMC lysate or (3) saline. As controls, six age and sex-matched mice were not submitted to SE-induction and received equal volume of saline (i.p).

\section{Isolation of BMMC and Transplantation}

GFP-transgenic mice were euthanized by cervical dislocation, under anesthesia with $200 \mu$ of $8 \%$ ketamine hydrochloride (Cristália) and $2 \%$ chlorpromazine (União Química Farmacêutica Nacional, São Paulo, Brazil). Fresh bone marrow was extracted from mouse femurs and tibiae by flushing with $1 \mathrm{ml}$ Dulbecco's Modified Eagle Medium (DMEM; Gibco, Grand Island, NY, USA) using a $25 \mathrm{G}$ needle. After centrifugation, cell pellet was resuspended with DMEM and fractionated on a density gradient generated by centrifugation over a Ficoll-Hypaque solution (GE Healthcare Life Sciences, Cleveland, OH, USA) at 1,500 $\mathrm{g}$ for $15 \mathrm{~min}$ at $15^{\circ} \mathrm{C}$. The mononuclear fraction was collected and washed twice with DMEM. Viable cells were counted by trypan blue exclusion using a Neubauer chamber. In order to generate BMMC lysate, BMMC $\left(1 \times 10^{7}\right.$ cells $\left./ \mathrm{ml}\right)$ were submitted to five freeze-thaw cycles (liquid nitrogen $/ 37^{\circ} \mathrm{C}$ water bath), as previously described [31].

The phenotypic characterization of BMMCs was performed by flow cytometry analysis. Briefly, BMMC were washed with PBS and incubated at $4{ }^{\circ} \mathrm{C}$ with fluorochrome-conjugated antibodies: CD34-PE, CD90-PE, CD45-APC, CD11b-APC, CD44-PE, CD117-Cy5, CD45APC, Sca1-Cy5 (anti-mouse, 1:100, BD Biosciences, Franklin Lakes, NJ, USA). Data acquisition and analysis were performed using a FACScalibur cytometer and the CellQuest software, respectively (BD Biosciences). At least 50,000 events were collected and analyzed. The described cell markers were present in BMMCs at the following frequencies: CD45 (96.3\%), CD11b (56.4\%), CD117 (1.1\%), CD34 (1.6\%) CD90 (3.1\%), CD44 $(97 \%)$ and Scal $(18 \%)$. 
One hour following diazepam administration, group (1) mice were injected with BMMC $\left(1 \times 10^{7}\right.$ cells $/ \mathrm{ml}$; total volume of $200 \mu \mathrm{l}$. BMMC lysate, in the same volume, was injected in group (2), while the control group (3), received a saline injection. In all groups, injections were performed via the retro-orbital plexus.

\section{Histological Analysis}

Mice were deeply anesthetized with ketamine $(100 \mathrm{mg} / \mathrm{kg}$ i.p.)/xylazine (10 $\mathrm{mg} / \mathrm{kg}$ i.p.) and euthanized at $4,8,12$, $24 \mathrm{~h}$ or 7 days following transplantation. The brains were harvested and immersed in $10 \%$ formaldehyde for $24 \mathrm{~h}$. After fixation, brains were dehydrated and embedded in paraffin. Serial coronal sections $(5 \mu \mathrm{m})$ were cut from at the specific coordinates of -1.28 to $-3.64 \mathrm{~mm}$ from bregma, according to Franklin and Paxinos [32], mounted on glass slides and air-dried. For immunostaining, the following primary antibodies were used: anti-NeuN (1:100, Chemicon international, Temecula, CA, USA), anti-GFAP (1:400, anti-glial fibrillary acidic protein, GFAP; Chemicon International), anti-vonWillebrand Factor (1:50, Zymed Laboratories, San Francisco, CA, USA) and Phalloidin-633 (1:200, Molecular Probes, Carlsbad, CA, USA). Primary antibodies were incubated overnight at $4{ }^{\circ} \mathrm{C}$. The next day, the following secondary antibodies were applied at a 1:200 dilution: anti-rabbit Alexa Fluor 568 conjugated, anti-rat Alexa Fluor 568 conjugated and StreptavidinAlexa Fluor 555 (all from Molecular Probes). Nuclei were counterstained with 4,6-diamidino-2-phenylindole (DAPI) (Vector Labs, Burlingame, CA, USA). Images were collected using a confocal microscope FluoView 1000 (Olympus, Tokyo, Japan).

The migration of donor cells to the brain was evaluated by either direct observation of $\mathrm{GFP}^{+}$cells by confocal microscopy analysis. For migration analysis, groups of mice were selected at 4,8 , and $24 \mathrm{~h}$ ( $\mathrm{n}=3$ per time point) following BMMC transplantation. Mice were transcardiacly perfused through the ascending aorta with saline, followed by $4 \%$ paraformaldehyde (PFA). Then, the left hemisphere was isolated and post-fixed with $4 \%$ PFA overnight, followed by a dehydration step by incubation in $30 \%$ sucrose solution for $24 \mathrm{~h}$. Then, the hemispheres were embedded in OCT and stored at $-80{ }^{\circ} \mathrm{C}$. The $\mathrm{GFP}^{+}$ cells were counted in nine equidistant sections of the brain, obtained at intervals of $100 \mu \mathrm{m}$. Left hemisphere sections were obtained from Bregma -1.28 to -3.64 , in the groups euthanized 4 and $8 \mathrm{~h}$ following cell transplantation. Sections were mounted with Vectashield mounting medium containing 4,6-diamidino-2-phenylindole (DAPI; Vector Laboratories, Burlingame, CA, USA) for nuclear counterstaining. Slides were analyzed and images were captured on a FV1000 confocal microscope (Olympus, Tokyo,
Japan). Data are expressed as number of $\mathrm{GFP}^{+}$cells per section (Mean \pm SEM).

For quantification of neuronal density, six equidistant coronal sections were obtained from each animal (from Bregma -1.28 to -2.67$)$, stained for NeuN, and analyzed in the rostral-caudal orientation. The images were obtained on a confocal microscope (FV1000; Olympus) with a $40 \times$ lens, and NeuN positive cells were counted within a framed area of $1,089 \mu^{2}$, using Image-Pro Plus analysis software v.7.0 (Media Cybernetics, Inc. Bethesda, MD, USA). Neuronal densities were calculated and corrected according to Abercrombie's formula [33-35]. Quantifications of neuronal densities were performed in the hippocampal subfields CA1, CA3 and hilus.

\section{Analysis of Cytokine Production and Gene Expression}

Total RNA was isolated from either the whole brain or isolated hippocampus with TRIzol reagent (Invitrogen), and the concentration was determined through photometric measurement. High Capacity cDNA Reverse Transcription Kit (Applied Biosystems, Foster City, CA) was used to synthesize cDNA from $1 \mu \mathrm{g}$ of RNA following the manufacturer's recommendations. qRT-PCR assays were performed to detect the expression levels of $T N F \alpha, I L-1 \beta, I L-4, I L-6, I L-10, N O S 2$, Chi3l3, MRC1, CCL22, CCL 17 and ARG1 genes. RT-qPCR amplification mixtures contained $20 \mathrm{ng}$ of cDNA template, $10 \mu \mathrm{l}$ of Taqman Master Mix (Applied Biosystems) with probes, and TNF- $\alpha$ (Mm00443258_m1), IL-1 $\beta$ (Mm004 34228_m1), IL-4 (Mm 00445259_m1) IL-6 (Mm0044 6190_m1) and IL-10 (Mm00439616_m1), Chi3l3 (Mm 00657889_mH), MRC1 (Mm 00485148_m1), CCL22 (Mm 00436439_m1),CCL17(Mm 00516136_m1) and ARG1 (Mm 00469812_m1) resulting in a final volume of $20 \mu \mathrm{l}$. To detect transplanted mouse BMMC, GFP expression was also evaluated. All reactions were performed in duplicate on an ABI7500 Sequence Detection System (Applied Biosystems) under standard thermal cycling conditions. Experiments with coefficients of variation greater than $5 \%$ were excluded. A no-template control (NTC) and no-reverse transcription control (No-RT) were also included. The results are presented as the fold-increase of expression from the individual mRNAs, with the target internal control $G A D P H$, using the cycle threshold method.

For quantification of GFP expression in the brain and isolated hippocampus, qPCR was performed in triplicate using a SybrGreen assay with primers for GFP (F-5'GCACG ACTTCTTCAAGTCCGCCATGCC $3^{\prime}$; R-5' GCGGATC TTGAAGTTCACCTTGATGCC $\left.3^{\prime}\right)$ and GAPDH (F-5'GAC TCCACTCACGGCAAATTCA $3^{\prime}$, R-5'CTGGAAGATGG TGATGGGCTTC $3^{\prime}$ ). Primer conditions were previously optimized to achieve between 1.98 and 2.0 amplification efficiency for both genes (data not shown). RT-qPCR was 
performed in a $20 \mu \mathrm{l}$ final volume using SybrGreen PCR master mix (Applied Biosystems, Foster City, CA), $0.2 \mu \mathrm{M}$ final concentration of each primer and $25 \mathrm{ng}$ of cDNA. Fold change expression was calculated as previously described [36].

Mice selected to be euthanized $24 \mathrm{~h}$ after SE were submitted to blood collection by cardiac puncture, under general anesthesia. Serum concentrations of TNF- $\alpha$, IL-4 and IL-10 were determined by an enzyme-linked immunosorbent assay (ELISA). All cytokines were measured in duplicate using specific antibody kits (R\&D Systems, Minneapolis, MN, USA) according to manufacturer's instructions.

\section{Statistical Analysis}

Data were expressed as mean $\pm \mathrm{SD}$ or mean $\pm \mathrm{SE}$, as indicates in figure legends. One-way analysis of variance and 2-way analysis of variance (ANOVA) with Tukey and Bonferroni post-tests were applied respectively, to assess the time variables of the treatment effectiveness. Statistical analysis was performed using Prism version 4.0 (Graph Pad Software, San Diego, CA, USA) software. Differences were considered significant with $p<0.05$.

\section{Results}

Pilocarpine-Induced SE and Mortality Rate of Mice

Administration of pilocarpine rapidly induced robust convulsive SE in mice (latency: $22 \pm 10 \mathrm{~min}$ ) that progressed to continuous category 5 seizures (i.e., SE). Thirty-five percent of the mice died during the first 3 days following SE, with no differences between experimental groups.

\section{BMMC Migration to the Brain}

Transplanted BMMC were found mainly in the perivascular areas $4 \mathrm{~h}$ post-SE, and began to be seen within the brain parenchyma $8 \mathrm{~h}$ post-SE. Quantification of BMMC in the brain demonstrated that numbers of $\mathrm{GFP}^{+}$cells were reduced by approximately $60 \%$ from 4 to $8 \mathrm{~h}$ following SE (Fig. 1c). In contrast, GFP expression increased in the hippocampus, comparing $4-8 \mathrm{~h}$ conditions. After $12 \mathrm{~h}$, levels of GFP mRNA were dramatically reduced (Fig. 1d). Twenty-four hours following $\mathrm{SE}, \mathrm{GFP}^{+}$cells were observed in the cortex, and in hippocampal subfields (Fig. 1e, f). Most $\mathrm{GFP}^{+}$cells were positive for CD11b, displayed a mononuclear phenotype, and did not express GFAP or NeuN (Fig. 1f, inset). While at $24 \mathrm{~h} \mathrm{GFP}^{+}$cells were frequently observed,and their presence was rarely detected 7 days after transplantation.
Evaluation of Neuronal Loss

A marked reduction in neuronal density of CA1, CA3 and DG hilus subfield of the hippocampus was observed in saline-treated, SE-induced mice when compared to non-SE control mice. The neuronal density in CA1 was preserved in mice treated with BMMC at $24 \mathrm{~h}$ and 7 days following SE (Fig. $2 \mathrm{a} ; p<0.001$ ) and in BMMC lysate at $24 \mathrm{~h}$ (Fig. $2 \mathrm{a} ; p<0.05$ ). A higher CA3 neuronal density was observed in mice treated with BMMC, $24 \mathrm{~h}$ and 7 days after SE. Treatment with BMMC, but not with BMMC lysate, preserved neuronal density in the DG hilus in mice at both time points analyzed (Fig. 2c).

BMMC-Induced Modulation of Cytokine Production and Gene Expression

To investigate the effects of BMMC transplantation in the inflammatory process within the brain following SE, cytokine gene expression was evaluated $12,24 \mathrm{~h}$ and 7 days post-SE. The highest expression of IL-1 $\beta$ was observed at $12 \mathrm{~h}$, whereas expression levels were not different in the non-SE control groups at $24 \mathrm{~h}$ and 7 days. Induction of SE resulted in the elevation of IL-6 and TNF $\alpha$ mRNA expression, when compared to non-SE controls at 12 and $24 \mathrm{~h}$ post-SE (Fig. 3 a, b, c). In BMMC-treated mice, results showed a significant downregulation of IL-1 $\beta$ expression at $24 \mathrm{~h}$ as well as in IL-6 at 12 and $24 \mathrm{~h}$ post-SE (Fig. 3a, b). TNF- $\alpha$ mRNA expression was significantly reduced in mice treated with BMMC and BMMC lysate, but only at $24 \mathrm{~h}$ post-SE induction (Fig. 3c).

The analysis of the anti-inflammatory cytokines IL-4 and IL-10 showed no increase in mRNA transcripts in SEinduced mice compared to non-SE controls in any of the time points analyzed (Fig. 3d, e, f). However, IL-4 mRNA expression was significantly increased $12 \mathrm{~h}$ after SE in mice treated with either BMMC or BMMC lysate (Fig. 3d and F0). IL-10 mRNA expression was significantly increased in mice treated with BMMC or BMMC lysate 12 and $24 \mathrm{~h}$ after SE induction compared to the non-SE control group and at $12 \mathrm{~h}$ compared to the SE-group (Fig. 3e).

In order to investigate the effects of BMMC in the periphery, cytokines serum levels were measured $24 \mathrm{~h}$ post-SE induction. A significant increase in TNF- $\alpha$, but not IL-4 or IL-10, was found in saline-treated mice when compared to non-SE mice (Fig. 4a). Treatment with BMMC resulted in a decrease in TNF- $\alpha$ levels (Fig. $4 a$ ). In addition, both IL-4 and IL-10 serum levels were increased in mice treated with BMMC or BMMC lysate group, when compared to saline-treated SE mice and to non-SE controls (Fig. 4b, c). 

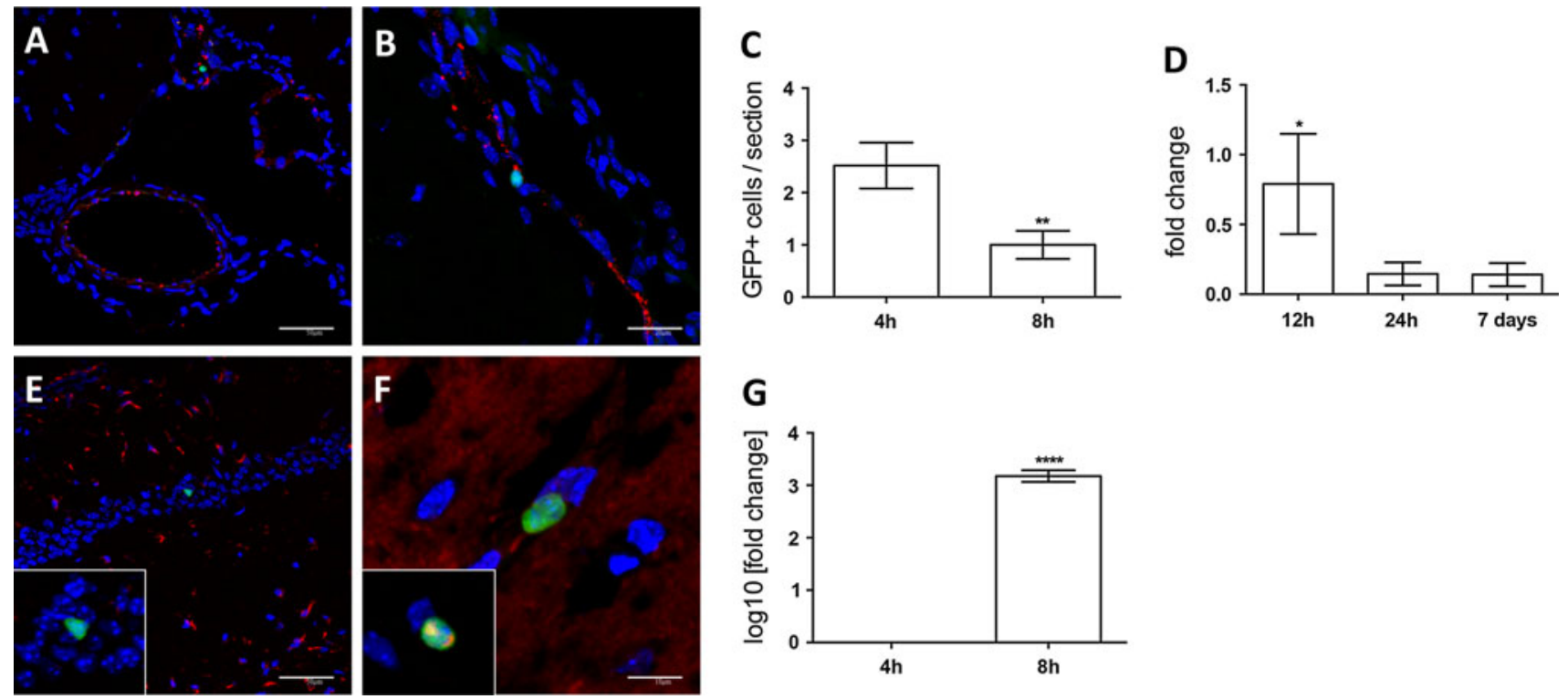

Fig. 1 Migration of BMMC to the brain after SE. Images show representative brain sections, at different time points following BMMC transplantation. a, b GFP ${ }^{+}$( green) $\mathrm{BMMC}$ in close proximity to vessels (von Willebrand factor staining in red) $4 \mathrm{~h}$ after transplantation. c Quantification of $\mathrm{GFP}^{+}$cells, by confocal microscopy analysis, in brain sections of mice euthanized 4 and $8 \mathrm{~h}$ following transplantation of BMMC. $\mathbf{d}$ Expression of GFP mRNA in the brain, at different time-points, evaluated by qPCR. e GFP ${ }^{+}$cells (inset) observed in hippocampal CA1 subfield (GFAP staining in red),

\section{Analysis of Gene Expression Associated} with Microglial Activation

The effects of BMMC transplantation on gene expression of markers from classic (type 1) and alternative (type 2) macrophages/microglia activation were evaluated. The expression levels of type 1-associated gene inducible nitric oxide synthase (NOS2), and type 2-associated genes Ym1 (Chi313), mannose receptor 1 (MRC1), arginase 1 (ARG1), in addition to chemokines CCL22 and CCL17 were determined (Fig. 5). Expression of NOS2 mRNA in brain tissues obtained from SE-saline group was markedly upregulated after 12 and $24 \mathrm{~h}$ of SE, compared to non-SE control group. Expression was higher in the SE-lysate group following $12 \mathrm{~h}$ when compared to the non-SE control and SE-saline groups (Fig. 5a). Injection of BMMC and BMMC lysate decreased mRNA expression of NOS2 at $24 \mathrm{~h}$ of SE (Fig. 5a).

CCL22 mRNA was increased in all groups $12 \mathrm{~h}$ after SE when compared to non-SE controls, followed by expression normalization at $24 \mathrm{~h}$ (Fig. 5b). Chi313 mRNA levels were significantly higher only in mice treated with BMMC lysate at $12 \mathrm{~h}$ and $24 \mathrm{~h}$ when compared to the non-SE control (Fig. 5c). The highest expression of CCL17 mRNA was observed at 12 and $24 \mathrm{~h}$ in all SE groups compared to

$24 \mathrm{~h}$ after transplantation of BMMCs. $\mathbf{f} \mathrm{GFP}^{+}$cells seen in hippocampal parenchyma (e F-actin staining in red) and expressed $\mathrm{CD} 11 \mathrm{~b}$ (inset) (CD11b staining in red). Sections were counterstained with DAPI (blue) for nuclear visualization. g Expression of GFP mRNA in the isolated hippocampus of mice euthanized 4 and $8 \mathrm{~h}$ following transplantation of BMMC, as evaluated by qPCR. The data represent the mean \pm SEM of 3-4 mice per group per timepoint. $* * * * p<0.0001 ; * * p<0.001, * p<0.05$. Scale bars $50 \mu \mathrm{m}(\mathbf{a}, \mathbf{e})$, $20 \mu \mathrm{m}$ (f) or $10 \mu \mathrm{m}$ (Color figure online)

the non-SE control group (Fig. 5d). MRC1 mRNA levels from BMMC and BMMC lysate groups were decreased at 12 and $24 \mathrm{~h}$ after SE onset compared to SE-saline (respectively, Fig. 5e). ARG1 mRNA expression was not significantly altered in any of the experimental groups (Fig. 5f).

\section{Discussion}

We recently demonstrated that BMMC are able to prevent epileptogenesis in the rat model, resulting in reduced seizures, neuronal loss, gliosis and abnormal network formation in the acute phase of TLE (Costa-Ferro et al. 2011). We also have previously reported that BMMC transplantation decreased proinflammatory cytokines levels (TNF- $\alpha$, IL- $1 \beta$ and IL-6) and increased anti-inflammatory cytokine (IL-10) levels in the brain and serum. Moreover, BMMC therapy reduced neuronal loss and gliosis, as well as increased the proliferation of newborn neurons in epileptic rats treated during the chronic phase. (Costa-Ferro et al. 2012). In the present study we investigated the effects of acute (i.v.) administration of BMMC and BMMC lysate following SE in mice. We found that BMMC significantly decreased cell death and modulated the production of critical inflammatory 

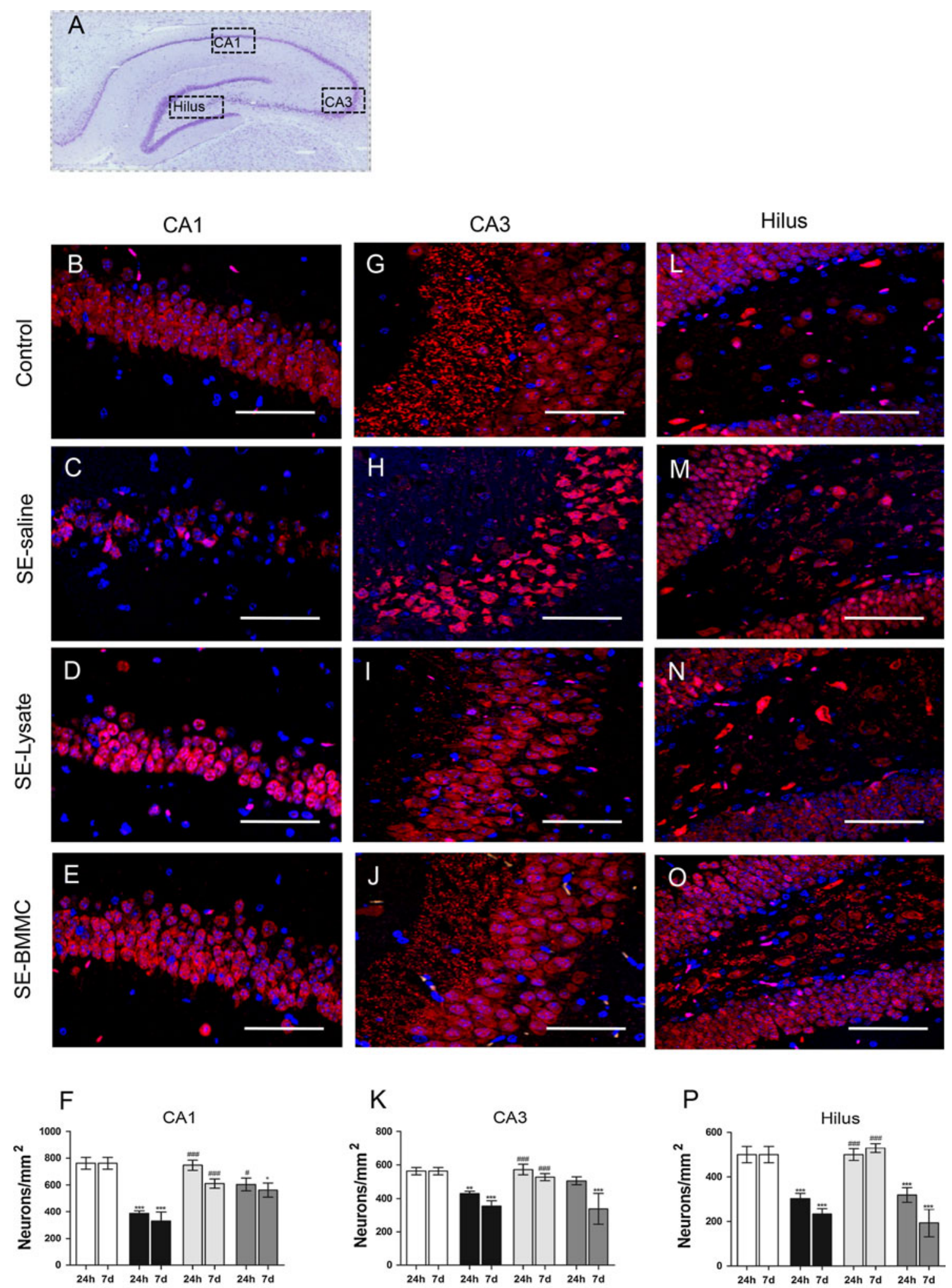

$\square$ Control $\square$ SE-Saline $\square$ SE-BMMC $\square$ SE-Lysate 
Fig. 2 Neuronal densities in selected hippocampal regions. Nisslstained section of the hippocampus, squares represent the evaluated areas a. Representative images of NeuN staining (red) in CA1 (b-e), CA3 $(\mathbf{g}-\mathbf{j})$, and DG hilus $(\mathbf{j}-\mathbf{o})$ in Control, SE-Saline, SE-Lysate, and SE-BMMC mice, $24 \mathrm{~h}$ after SE. Nuclei are counterstained with DAPI (blue). Scale bar $50 \mu \mathrm{m}$. Neuronal hippocampal cell densities were quantified $24 \mathrm{~h}$ and 7 days after SE in CA1 area (f); CA3 area (k); dentate gyrus $(\mathbf{p})$. $* * * p<0.001 ; * * p<0.01 ; * p<0.05$ : statistical analysis of each group compared to control and ${ }^{\# \#} p<0.001$; ${ }^{\#} p<0.05$, compared to SE-saline groups. The data represent the mean \pm SEM of 5 mice per group analyzed by two-way ANOVA and post hoc Bonferroni test (Color figure online)

mediators, despite the absence of BMMC differentiation into neurons in damaged areas.

Sparse populations of BMMC were found in the hippocampal and cortical regions in the hours following transplantation, and were almost completely lost 7 days after SE induction. We have previously studied the migration of BMMC transplanted at different time points post-SE, and reported that a small number of these cells migrate and remain within the brain [27, 37]. In fact, it has been shown that intravenously transplanted BMMC primarily migrate to the bone marrow, spleen and lungs. However, apart from the hypothesis that BMMC can promote a bystander effect in the brain through the release of trophic factors and cytokines promoting tissue repair and regeneration, it is also possible that these cells exert peripheral actions resulting in repercussions in the brain, as previously shown [38]. Here we demonstrated a reduction in the inflammatory cytokine, $\mathrm{TNF}-\alpha$, and increased levels of anti-inflammatory cytokines, IL-10 and IL-4 in the periphery, which may reflect the modulation of cytokine production in the brain as well as systemically.
A
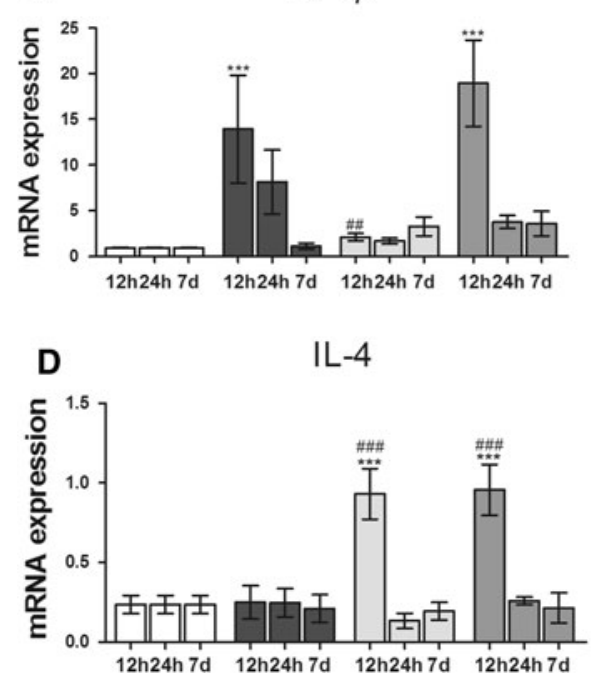

B

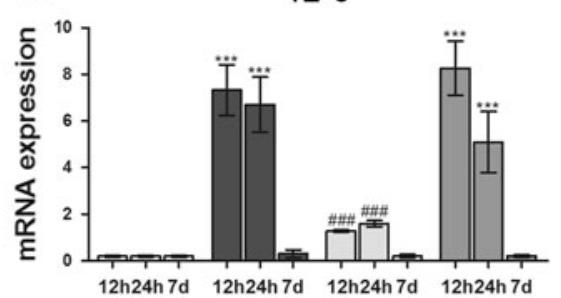

IL-10

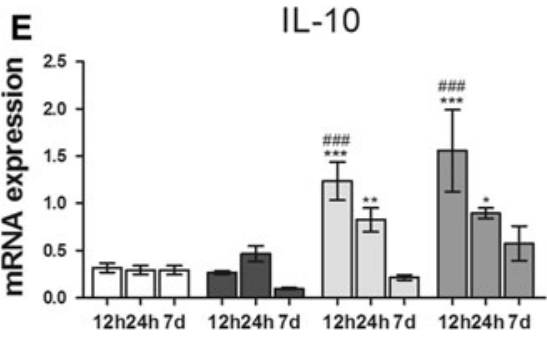

C
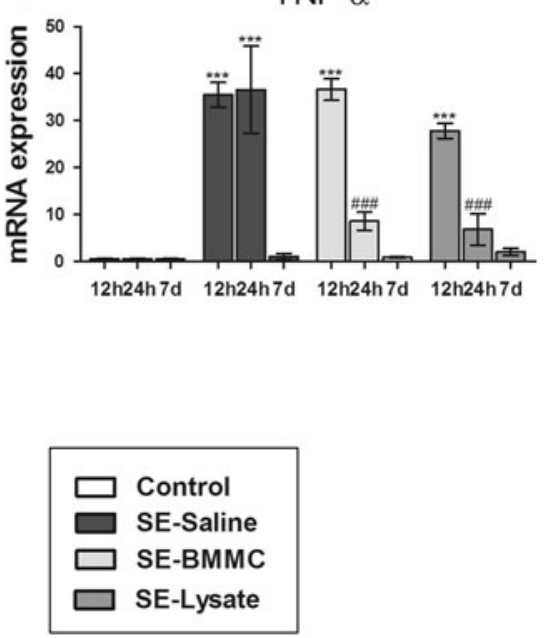

Fig. 3 mRNA expression in brain tissue at different time points after status epilepticus induction. IL-1 $\beta$ (a), IL-6 (b), TNF- $\alpha$ (c), IL-4 (d) and IL-10 (e) expression was analyzed in brains at 12, $24 \mathrm{~h}$ and 7 days after SE. Symbols represent the mean \pm SEM; $n=5-7$ mice per group. $* * * p<0.001 ; * * p<0.01 ; * p<0.05$ versus control group and \#\#\# $p<0.001 ;{ }^{\# \#}<0.01$ versus SE-saline group (two-way ANOVA and post hoc Bonferroni test)

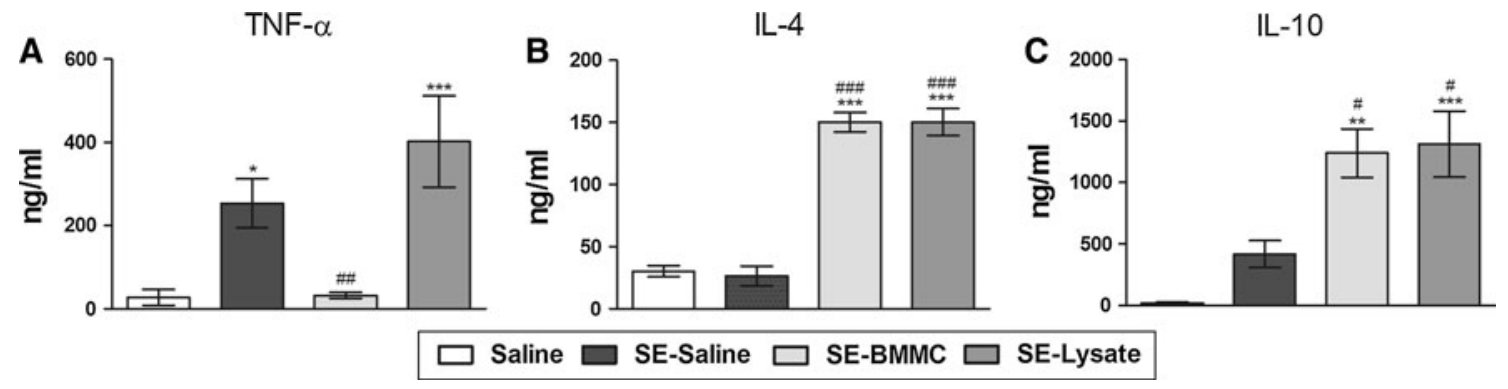

Fig. 4 Effects of BMMC in serum cytokine levels. Serum TNF- $\alpha$ (a), IL-4 (b), and IL-10 (c) levels $24 \mathrm{~h}$ after SE were assayed by ELISA. Symbols represent the mean \pm SEM of 5-6 mice per group. Data were analyzed by one-way ANOVA and Tukey's multiple comparison test. $* * * p<0.001 ; * * p<0.01 ; * p<0.05$ versus control and ${ }^{\# \# \# p}<0.001 ;{ }^{\#} p<0.05$ versus SE-saline groups 
Fig. 5 Analysis of gene expression associated with microglial activation.

Expression of a Nitric oxide synthase 2 (NOS2), b C-C motif chemokine 22 (CCL22), c chitinase 3-like 3 (Chi313), d Chemokine (C-C motif) ligand 17 (CCL 17), e Mannose receptor (MRC1), and f Arginase 1 genes in the brain $12 \mathrm{~h}$ and $24 \mathrm{~h}$ after SE. The mRNA expression is quantified by real-time PCR and normalized to the levels of GAPDH. Symbols represent the mean $\pm \mathrm{SEM} ; \mathrm{n}=5-8$ mice per group. $* * * p<0.001$; $* * p<0.01 ; * p<0.05$ versus control group and ${ }^{\# \#} p<0.001$; ${ }^{\#} p<0.05 ;{ }^{\#} p<0.01$ versus SE-saline group (two-way ANOVA and post hoc Bonferroni test)
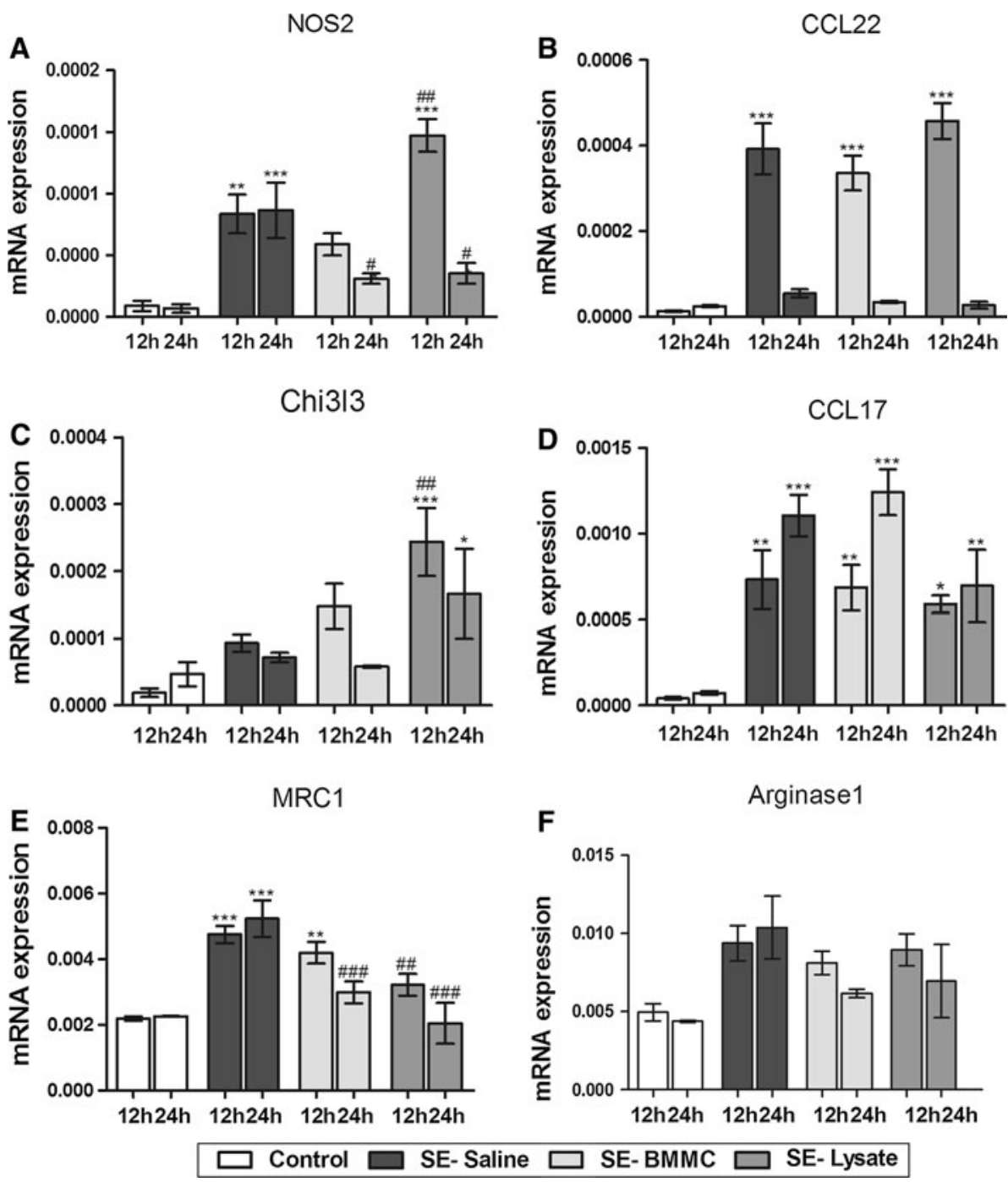

Neuronal loss, resulting from SE, may influence the process of epileptogenesis. Therefore, neuroprotection may have an antiepileptogenic function. In the present study, we showed that neurodegeneration affected mainly the hippocampal subfields CA1, CA3 and DG hilus, and that administration of BMMC shortly after SE exerted neuroprotective effects. Neuroprotection is one of the described effects promoted by bone marrow cells in different experimental settings [39-41]. However, cell therapy can act through a number of other paracrine actions that may impact the pathogenesis of the disease, including neuroinflammation modulation [37].

There is evidence that neuroinflammation can contribute to neuronal death and the formation of hyper excitable circuits [6]. Although microglia is the primary cells of the innate immunity in the brain, astrocytes are also known sources of inflammatory cytokines in the brain. Microglial cells are activated by the binding of pattern recognition receptors to damage-associated molecular patterns (DAMPs). In fact, following SE, neuronal death generates
DAMPs which trigger microglia activation in an experimental model of epilepsy [14].

In addition to its neurodegenerative effects, we demonstrated that SE up-regulates the expression of genes related to inflammation and classical (type 1) activation of microglia/macrophages. As previously seen in experimental models of epilepsy, this phenomenon is often associated with extensive neuronal injury and production of IL-1 $\beta$, through classically activated microglial cells [42, 43]. Other reports have shown that inflammatory mediators were elevated in the brain shortly after SE, including $\mathrm{TNF} \alpha$, which is highly expressed following seizure [10, 44], and IL-6, shown to be rapidly elevated in the hippocampus [45]. In this study we analyzed the expression of genes associated with inflammation in the brain 12, $24 \mathrm{~h}$ and 7 days post-SE and observed that transplantation with BMMC led to the reduced expression of IL- $1 \beta$, IL- 6 and $\mathrm{TNF} \alpha$, indicating a suppressive effect on the production of pro-inflammatory cytokines following SE. 
Reduced neuronal loss by itself may cause a decrease in classical activation of microglia and neuroinflammation. In a chronic model of epilepsy, BMMC decreased the expression of TNF $\alpha$, IL-1 $\beta$ and IL-6, which are known to exacerbate the disease in its chronic phase [37]. Here, we showed that modulation of the inflammatory response during epileptogenesis is also a mechanism of action of BMMC when transplanted after SE. Moreover, we observed an increased expression of anti-inflammatory mediators, such as IL-4 and IL-10. Previous studies have suggested that bone marrowderived cells are able to release several trophic factors and cytokines that are involved in tissue repair and regeneration in the injured brain $[6,37,38,46]$.

Among the inflammatory mediators evaluated in this study, NOS2 mRNA, characteristic of type 1 microglia, was inhibited by transplanted BMMC exclusively at the $24 \mathrm{~h}$ post-SE time point. The type 2 activation macrophage marker, mannose receptor 1 (MRC1), was decreased at $24 \mathrm{~h}$ post-BMMC transplantation. The expression of other genes related to type 2 activation was not modulated by BMMC transplantation when compared to the SE-saline group. However, all of the type 2-associated genes that were evaluated demonstrated an increase in expression in every group, post-SE induction. This is consistent with the activation of a physiologic, negative feedback, anti-inflammatory response, concomitant to the inflammatory response that follows SE. The suppression of type 1-associated genes, along with the observation of increased expression of type 2 activation genes, in BMMC-treated mice suggests a polarization towards the alternative activation. A recent study also showed that BMMC transplantation increases the expression of the mannose receptor in phagocytic macrophages/ microglia within the lesion boundary zone in the unilateral focal cortical ischemia model [45].

To investigate whether the protective effects of BMMC were dependent on cellular integrity or soluble factors derived from the cells, the administration of BMMC lysate was also assessed. BMMC lysate induced an effect similar to BMMC in some parameters, such as prevention of neuronal cell loss in the CA1 region $24 \mathrm{~h}$ post-SE. The effects of BMMC lysate demonstrated in this study were, in some aspects absent, partial or comparable to the effects of viable BMMC, which could be explained by the fact that live cells may release protective mediators over an extended period. In fact, increased blood-brain barrier permeability is involved in the establishment of SE and it is also sustained by it, thus allowing the entrance of soluble factors and cells into the CNS [10].

In conclusion, the present study provides experimental evidence that suggests that BMMC transplantation promotes neuroprotection by modulating the production of important inflammatory mediators, which are known to play a role in epileptogenesis.
Acknowledgments This work was supported by the Brazilian National Research Council (CNPq), Centro de Pesquisa Gonçalo Muniz (CPQGM-FIOCRUZ), Centro de Biotecnologia e Terapia Celular do Hospital São Rafael (CBTC), FAPESB and FINEP.

Conflict of interests The authors declare that they have no competing interests.

\section{References}

1. Voutsinos-Porche B, Koning E, Kaplan H, Ferrandon A, Guenounou M, Nehlig A et al (2004) Temporal patterns of the cerebral inflammatory response in the rat lithium-pilocarpine model of temporal lobe epilepsy. Neurobiol Dis 17(3):385-402

2. Turski L, Ikonomidou C, Turski WA, Bortolotto ZA, Cavalheiro EA (1989) Cholinergic mechanisms and epileptogenesis. The seizures induced by pilocarpine: a novel experimental model of intractable epilepsy. Synapse 3(2):154-171

3. Persinger MA, Makarec K, Bradley JC (1988) Characteristics of limbic seizures evoked by peripheral injections of lithium and pilocarpine. Physiol Behav 44(1):27-37

4. Matzen J, Buchheim K, van Landeghem FK, Meierkord H, Holtkamp M (2008) Functional and morphological changes in the dentate gyrus after experimental status epilepticus. Seizure 17(1):76-83

5. Fountain NB (2000) Status epilepticus: risk factors and complications. Epilepsia 41:S23-S30

6. Vezzani A, French J, Bartfai T, Baram TZ (2011) The role of inflammation in epilepsy. Nat Rev Neurol 7(1):31-40

7. Li G, Bauer S, Nowak M, Norwood B, Tackenberg B, Rosenow F et al (2011) Cytokines and epilepsy. Seizure 20(3):249-256

8. Friedman A, Dingledine R (2011) Molecular cascades that mediate the influence of inflammation on epilepsy. Epilepsia $52: 33-39$

9. van Gassen KL, de Wit M, Koerkamp MJ, Rensen MG, van Rijen PC, Holstege FC et al (2008) Possible role of the innate immunity in temporal lobe epilepsy. Epilepsia 49(6):1055-1065

10. Ravizza T, Gagliardi B, Noe F, Boer K, Aronica E, Vezzani A (2008) Innate and adaptive immunity during epileptogenesis and spontaneous seizures: evidence from experimental models and human temporal lobe epilepsy. Neurobiol Dis 29(1):142-160

11. Yamamoto A, Schindler CK, Murphy BM, Bellver-Estelles C, So NK, Taki W et al (2006) Evidence of tumor necrosis factor receptor 1 signaling in human temporal lobe epilepsy. Exp Neuro 202(2):410-420

12. Vezzani A, Moneta D, Conti M, Richichi C, Ravizza T, De Luigi A et al (2000) Powerful anticonvulsant action of IL-1 receptor antagonist on intracerebral injection and astrocytic overexpression in mice. Proc Natl Acad Sci USA 97(21):11534-11539

13. Marchi N, Teng Q, Ghosh C, Fan Q, Nguyen MT, Desai NK et al (2010) Blood-brain barrier damage, but not parenchymal white blood cells, is a hallmark of seizure activity. Brain Res 1353:176-186

14. Maroso M, Balosso S, Ravizza T, Liu J, Aronica E, Iyer AM et al (2010) Toll-like receptor 4 and high-mobility group box-1 are involved in ictogenesis and can be targeted to reduce seizures. Nat Med 16(4):413-419

15. Keimpema E, Fokkens MR, Nagy Z (2009) Early transient presence of implanted bone marrow stem cells reduces lesion size after cerebral ischaemia in adult rats. Neuropathol Appl Neurobiol 35(1):89-102

16. Chang YC, Shyu WC, Lin SZ, Li H (2007) Regenerative therapy for stroke. Cell Transplant 16(2):171-181

17. Li Y, Chen J, Chen XG, Wang L, Gautam SC, Xu YX et al (2002) Human marrow stromal cell therapy for stroke in rat: neurotrophins and functional recovery. Neurology 59(4):514-523 
18. Harrop JS, Hashimoto R, Norvell D, Raich A, Aarabi B, Grossman RG, Guest JD, Tator CH, Chapman J, Fehlings MG (2012) Evaluation of clinical experience using cell-based therapies in patients with spinal cord injury: a systematic review. J Neurosurg Spine 17(1):230-246

19. Mahmood A, Wu H, Qu C, Xiong Y, Chopp M (2013) Effects of treating traumatic brain injury with collagen scaffolds and human bone marrow stromal cells on sprouting of corticospinal tract axons into the denervated side of the spinal cord. J Neurosurg 118(2):381-389

20. Saccardi R, Mancardi GL, Solari A, Bosi A, Bruzzi P, Di Bartolomeo P et al (2005) Autologous HSCT for severe progressive multiple sclerosis in a multicenter trial: impact on disease activity and quality of life. Blood 105(6):2601-2607

21. Van Wijmeersch B, Sprangers B, Rutgeerts O, Lenaerts C, Landuyt W, Waer M (2007) Allogeneic bone marrow transplantation in models of experimental autoimmune encephalomyelitis: evidence for a graft-versus-autoimmunity effect. Biol Blood Marrow Transplant 13(6):627-637

22. Guo J, Shen JK, Wang L, Xiao L, Zhang RJ, Luo WF et al (2011) In vivo evaluation of cerebral transplantation of resovist-labeled bone marrow stromal cells in Parkinson's disease rats using magnetic resonance imaging. Appl Biochem Biotechnol 163(5):636-648

23. Lee JK, Schuchman EH, Jin HK, Bae JS (2012) Soluble CCL5 derived from bone marrow-derived mesenchymal stem cells and activated by amyloid $\beta$ ameliorates Alzheimer's disease in mice by recruiting bone marrow-induced microglia immune responses. Stem Cells 30(7):1544-1555

24. Moraes L, Vasconcelos-dos-Santos A, Santana FC, Godoy MA, Rosado-de-Castro PH, Jasmin G et al (2012) Neuroprotective effects and magnetic resonance imaging of mesenchymal stem cells labeled with SPION in a rat model of Huntington's disease. Stem Cell Res 9(2):143-155

25. Corti S, Locatelli F, Donadoni C, Guglieri M, Papadimitriou D, Strazzer S et al (2004) Wild-type bone marrow cells ameliorate the phenotype of SOD1-G93A ALS mice and contribute to CNS, heart and skeletal muscle tissues. Brain 127:2518-2532

26. Martínez HR, Molina-Lopez JF, González-Garza MT, MorenoCuevas JE, Caro-Osorio E, Gil-Valadez A et al (2012) Stem cell transplantation in amyotrophic lateral sclerosis patients: methodological approach, safety, and feasibility. Cell Transplant 21(9):1899-1907

27. Costa-Ferro ZS, Vitola AS, Pedroso MF, Cunha FB, Xavier LL, Machado DC et al (2012) Prevention of seizures and reorganization of hippocampal functions by transplantation of bone marrow cells in the acute phase of experimental epilepsy. Seizure 19(2):84-92

28. Venturin GT, Greggio S, Marinowic DR, Zanirati G, Cammarota M, Machado DC et al (2011) Bone marrow mononuclear cells reduce seizure frequency and improve cognitive outcome in chronic epileptic rats. Life Sci 15(7-8):229-234

29. Longo B, Romariz S, Bianco MM, Vasconcelos JF, Bahia L, Soares MB et al (2010) Distribution and proliferation of bone marrow cells in the brain after pilocarpine-induced status epilepticus in mice. Epilepsia 51(8):1628-1632

30. Racine RJ (1972) Modification of seizure activity by electrical stimulation, I: after- discharge threshold. Electroencephalogr Clin Neurophysiol 32:269-279
31. Bachleitner-Hofmann T, Strohschneider M, Krieger P, Sachet M, Dubsky P, Hayden H et al (2006) Heat shock treatment of tumor lysate-pulsed dendritic cells enhances their capacity to elicit antitumor $\mathrm{T}$ cell responses against medullary thyroid carcinoma. J Immunol 91(11):4571-4577

32. Franklin K, Paxinos G (1997) The mouse brain in stereotaxic coordinates. Academic Press, San Diego

33. Abercrombie M (1946) The density of neurones in the human hippocampus. Anat Rec 94:239-247

34. Goodman JH (1998) Experimental models of status epilepticus. Neuropharmacol Method Epilepsy Res New York, CRC Press, p 97-125

35. Cavalheiro EA, Naffah-Mazacoratti MG, Mello LE, Leite JP (2006) The pilocarpine model of seizures. In: Pitkanen A, Schwartzkroin PA, Moshé SL (eds) Models of seizures and epilepsy. Elsevier, Amsterdam, pp 433-444

36. Pffafl MW (2001) A new mathematical model for relative quantification in real-time RT-PCR. Nucleic Acids Res 29(9):e45

37. Costa-Ferro ZSM, Souza BSF, Leal MMT, Kaneto CM, Azevedo CM, Da Silva IC et al (2012) Transplantation of bone marrow mononuclear cells decreases seizure incidence, mitigates neuronal loss and modulates pro-inflammatory cytokine production in epileptic rats. Neurobiol Dis 46(2):302-313

38. de Freitas Souza BS, Nascimento RC, de Oliveira SA, Vasconcelos JF, Kaneto CM, de Carvalho LF et al (2012) Transplantation of bone marrow cells decreases tumor necrosis factor- $\alpha$ production and blood-brain barrier permeability and improves survival in a mouse model of acetaminophen-induced acute liver disease. Cytotherapy 14(8):1011-1021

39. Yoshihara T, Ohta M, Itokazu Y, Matsumoto N, Dezawa M, Suzuki Y et al (2007) Neuroprotective effect of bone marrowderived mononuclear cells promoting functional recovery from spinal cord injury. J Neurotrauma 24(6):1026-1036

40. Sharma S, Yang B, Strong R, Xi X, Brenneman M, Grotta JC et al (2010) Bone marrow mononuclear cells protect neurons and modulate microglia in cell culture models of ischemic stroke. J Neurosci Res 88(13):2869-2876

41. Cardoso MM, Franco EC, de Souza CC, da Silva MC, Gouveia A, Gomes-Leal W (2013) Minocycline treatment and bone marrow mononuclear cell transplantation after endothelin-1 induced striatal ischemia. Inflammation 36(1):197-205

42. Allan SM, Tyrrenll PJ, Rothwell NJ (2005) Interleukin-1 and neurnal injury. Nat Rev Immunol 5(8):629-640

43. Rijkers K, Majoie HJ, Hoogland G, Kenis G, De Baets M, Vles JS (2009) The role of interleukin-1 in seizures and epilepsy: a critical review. Exp Neurol 216(2):258-271

44. Plata-Salamãn CR, Ilyin SE, Turrin NP, Gayle D, Flynn MC, Romanovitch AE et al (2000) Kindiling modulates the IL-1 beta system, TNFalpha, TGF-beta1 and neuropeptide mRNAs in specific brain regions. Brain Res Mol Brain Res 75(2):248-258

45. Kalueff AV, Lehtimaki KA, Ylinen A, Honkaniemi J, Peltola J (2004) Intranasal administration increases of IL-6 increased the severity of chemically induced seizures in rats. Neurosci Lett 365(2):106-110

46. Giraldi-Guimarães A, de Freitas HT, Coelho Bde P, MacedoRamos H, Mendez-Otero R, Cavalcante LA et al (2012) Bone marrow mononuclear cells and mannose receptor expression in focal cortical schema. Brain Res 452:173-184 